\title{
ASSESSMENT OF THE OPINIONS AND ATTITUDES OF MEDICAL STUDENTS TOWARDS LGBTQIA+ INDIVIDUALS
}

Fatih Erkan Akay ${ }^{1}$, Beliz Koçyiğit ${ }^{1}$, Amila Kafadar ${ }^{2}$, Beril Ay ${ }^{3}$, Kaan Çifcibaşı ${ }^{4}$, Çağrı Girit ${ }^{1}$, Nazlıcan Kükürtcü̈ Berra Kurtoğlu ${ }^{6}$, Bengisu Gür7 , Serdar Öztora ${ }^{8}$

\author{
${ }^{1}$ Trakya University School of Medicine, Edirne, TURKEY \\ ${ }^{2}$ Sarajevo University School of Medicine, Sarajevo, BOSNIA AND HERZEGOVINA \\ ${ }^{3}$ Acıbadem University School of Medicine, Istanbul, TURKEY \\ ${ }^{4}$ Ludwig Maximilian University School of Medicine, Munich, GERMANY \\ ${ }^{5}$ Akdeniz University School of Medicine, Antalya, TURKEY \\ ${ }^{6}$ TOBB University of Economics and Technology School of Medicine, Ankara, TURKEY \\ ${ }^{7}$ Bezmialem Vakif University Faculty of Medicine, Istanbul, TURKEY \\ ${ }^{8}$ Department of Family Medicine, Trakya University School of Medicine, Edirne, TURKEY
}

\begin{abstract}
Aims: The aim of this multicentral study is to analyze the opinions and attitudes of medical students towards lesbian, gay, bisexual, transgender, queer, intersex, and asexual individuals. Methods: A total of 1116 medical students from 59 universities in Turkey, 1 from Bosnia and Herzegovina, and 7 universities from Germany have participated in this study. The questionnaire consisted of 23 multiple-choice questions and an open-ended question. Data about the comparison of 1st and 6th year medical students were analyzed using the Pearson Chi-Squared test and the Fisher Exact test in IBM SPSS version 23.0.00. Results: The mean age of the participants was $21.2 \pm 2.1$ years (range: 17-34 years). There were 693 female, 417 male, 3 nonbinary, and 1 queer participants, and two did not declare their gender. There were 263 (23.6\%) 1st year, 315 (28.3\%) 2nd year, 179 (16.0\%) 3rd year, $112(10.0 \%)$ 4th year, $98(8.8 \%)$ 5th year, and $139(12.5 \%)$ 6th year students. There were $10(0.9 \%)$ missing data. In the 15th question asking whether LGBTQIA+ individuals have the right to adoption or not, the 18th question asking if their school is providing education on sexual health, the 19th question asking if they consider themselves educated about safe sexual intercourse as an individual, and the 22nd question asking if they think that LGBTQIA+ individuals are more prone to catching sexually transmitted diseases, there were a significant difference between 1st graders and 6th graders. Conclusion: PIn conclusion, though the majority of answers given indicate a positive approach towards LGBTQIA+ individuals, it can be stated that the attitude of medical students towards LGBTQIA+ individuals is by far suboptimal. Keywords: Medical student, sexual orientation, gender identity, LGBTQIA+
\end{abstract}

\section{INTRODUCTION}

What exactly causes a person's sexual orientation and gender identity still has an ambiguous background. There has been a growing number of studies in recent years concerning the genetic nature of lesbians, gays, bisexuals, transgenders, queers, intersexes, and asexuals (LGBTQIA+) with great attention on the possibility of genetic origins (1). It was considered a psychological disorder for many years. The turning point of
LGBTQIA+ history was when homosexuality was removed as a diagnostic category by the American Psychiatric Association in 1973 (2). It was then completely removed from the Diagnostic and Statistical Manual of Mental Disorders (DSM) in 1980 (2, 3). However, bias opinions are still present within professionals about how the LGBTQIA+ population should be considered in society (4). The attitudes physicians present are important due to the crucial role they play in society. Health care differences related to the LGBTQIA+ po- 
pulations are drawing more attention to the medical community. Health issues affecting the LGBTQIA+ population have been neglected and faintly studied throughout history $(5,6)$.

Patients of LGBTQIA+ community may present a challenge for physicians due to the high rates of psychiatric disorders, unreported domestic violence, substance abuse, and attempts of suicide which have been associated with the health care differences that are linked to social stigma, discrimination, and denial of human rights within the LGBTQIA+ population (7). LGBTQIA+ individuals often receive standard care, but may also be denied for care due to their sexual orientation or gender identity when compared to non-LGBTQIA+ patients (8). Furthermore, many health care professionals believe they are untrained or unprepared to care for LGBTQIA+ patients, and that differences in their treatment exist (9). Medical schools may present a great opportunity in reducing this gap with an early exposure to an environment that will include diverse patients along with different opinions, attitudes, and behaviors (10). Evidence also proves that LGBTQIA+ patients may be uncomfortable admitting their sexual orientation to physicians in fear of unfair treatment (11). This lack of disclosure may lead to a poor relationship between the patient and the physician. Consequently, the likelihood for an LGBTQIA+ patient to be treated wrongfully is significantly higher (12).

This multicentral study aims to analyze the different opinions and attitudes of medical students towards LGBTQIA+ individuals.

\section{MATERIAL AND METHODS}

Our multicentral, observational, and questionnaire-based study was approved by the Scientific Research Ethics Committee of Trakya University School of Medicine (Protocol Code: TÜTF-BAEK 2019/355). The research was carried out between April and May 15th, 2020. The questionnaire was sent to the students through each university's Scientific Research Society and European Medical Students' Association (EMSA). The study population was composed of undergraduate medical students. A total of 1116 medical students from 59 universities in Turkey, 1 from Bosnia and Herzegovina, and 7 universities from Germany have participated in the research. The questionnaire was conducted via Google Forms and included an informed consent section.

The questionnaire consisted of 24 questions. Multiple-choice questions and an open-ended question were used. In the questionnaire, sociodemographic data such as gender, age, school, grade, sexual orientation, and incline towards religion as well as their view on LGBTQIA+ community personally and as a future medical professional were questioned. The overall questionnaire is shown in Table 1.

The data were analyzed with IBM SPSS version 23.0.00. Categorical data (grade, school, sexual orientation, and gender identity together with the answers given) were stated as numbers and percentages. Continuous data (age) were stated as mean, standard deviation and range. Data about the comparison of 1 st and 6th year medical students were analyzed using the Chi-Squared test, Pearson Chi-Squared test, and the Fisher Exact test. A p-value $<0.05$ was set for statistical significance.

\section{RESULTS}

This questionnaire-based study was conducted among 1116 medical students. The average of the participants' age was 21.2 years (standard deviation [SD]: 2.145 years, range: $17-34$ years). The gender range of the participants is as follows: 693 females, 417 males, 3 nonbinaries and 1 queer. Two of them did not declare their gender. Ten participants did not declare their grades. The distribution of grades is shown in Table 2.

Forty students (3.6\%) from Bosnia and Herzegovina, 41 (3.8\%) students from Germany, and 1035 (92.6) students from Turkey have participated in the research. There were 11 (\%1) missing data.

Three hundred and ninety-seven (35.6\%) of the students identified themselves as religious and $718(64.3$ $\%)$ of them as non-religious. There was $1(0.1 \%)$ missing data. The participants were asked what their sexual orientations were, and their answers are shown in Table 3.

The 7th question was asking whether they had a friend or a family member from the LGBTQIA+ community. Out of 1116 participants, 639 (57.3\%) of them stated that they had whereas $476(42.7 \%)$ of them stated that they did not, there was $1(0.1 \%)$ missing data. While $1001(89.7 \%)$ of the participants said that they would accept an LGBTQIA+ individual as a friend, $114(10.2 \%)$ answered that they would not. There was $1(0.1 \%)$ missing data. Two hundred and fifty-seven $(23.0 \%)$ students thought LGBTQIA+ individuals are psychologically ill and needed therapy, 856 (76.7\%) of them did not. There were $3(0.3 \%)$ missing data.

Eight hundred and eighty-two (79.0\%) students stated that it would have been beneficial for our society to accept LGBTQIA+ individuals as "normal", while 232 $(20.8 \%)$ of them stated that it would not. There were 2 $(0.2 \%)$ missing data. 
Table 1: The questionnaire used in this study.

Questions

Answers
1) Gender
2) Age
3) Which school are you currently enrolled in?
4) What year are you currently enrolled in?
5) Do you consider yourself a religious person?
6) What is your sexual orientation?

7) Is there someone who is LGBTQIA+ among your friends, relatives or people around you?

8) Would you accept an LGBTQIA+ individual as your friend?

9) Do you think LGBTQIA+ people have psychological disorders and need therapy?

10) Do you think that accepting LGBTQIA+ individuals as "normal" will benefit our society?

11) Do you find it appropriate to allow LGBTQIA+ individuals to work with children?

12) Do you think LGBTQIA+ individuals are mistreated in your society?

13) Do you think LGBTQIA+ individuals should be fully accepted in our society?

14) Do you think LGBTQIA+ individuals have the right to get married?

15) Do you think LGBTQLA+ individuals should have the right to adopt?

16) Does same-sex marriage endanger the ideology of a family?

17) What are the sexual behaviours of LGBTQIA+ individuals according to your own opinion? (You can select one or more options.)

18) Does your school educate you about sexual health?

19) Do you consider yourself well educated on the topic of safe sex?

20) Do you think there is a need for more guidance and training for your approach to LGBTQIA+ individuals as a physician?

21) Would you refuse to see a patient because they are an LGBTQIA+ individual?

22) Do you think LGBTQIA+ individuals are more prone to catching sexually transmitted diseases?

23) Do you think you would approach patients differently if they lived a life you do not agree with?

24) Please explain in a few short sentences how you would approach an LGBTQLA+ patient.

$$
\text { Yes / No }
$$

Heterosexual / Homosexual / Bisexual / Asexual /

Other / I do not prefer to specify / Other

$$
\text { Yes / No }
$$

Yes / No

Yes / No

Yes / No

Yes / No

Yes / No

Yes / No

Yes / No / Other

Yes / No / Other

Yes / No / Other

Same as heterosexual individuals / More promiscuous /

More risky and unprotected sexual intercourse / Safer /

Other

Yes / No / Other

Yes / No / Other

Yes / No / Other

Yes / No / Other

Yes / No / Other

Yes / No 
The participants were asked whether it was deemed appropriate to allow LGBTQIA+ individuals to work with children. The answers were 876 (78.5\%) "Yes" and 239 (21.4\%) "No". There was $1(0.1 \%)$ missing data. Nine hundred and ninety-two $(88.9 \%)$ of the participants thought that LGBTQIA+ were being abused in our society, while $123(11.0 \%)$ of the participants thought that this was not the case according to the 12th question. There was $1(0.1 \%)$ missing data. In addition, while 874 (78.3\%) people believed that LGBTQIA+ individuals should be fully accepted in our society, the rest of them (240, 21.5\%) insisted that they should not be accepted. There were $2(0.2 \%)$ missing data.

Question 14 was asking if LGBTQIA+ individuals have the right to marry. In the 15th question, it was asked whether LGBTQIA+ individuals should have the right for adoption. The answers that are given to question 14 and 15 are listed in Table 4.

Seven hundred forty (66.3\%) participants thought that same-sex marriage does not endanger the concept/ ideology of a family, $341(30.6 \%)$ of them defended it does, $19(1.7 \%)$ of them thought it somewhat does, 8 $(0.7 \%)$ of them were indecisive, $4(0.4 \%)$ of them did not have a particular idea, and there $4(0.4 \%)$ missing data.

The participants were asked how are the sexual behaviors of LGBTIA+ individuals according to their thoughts (Table 5). The participants could choose more than one choice according to their ideas.

It was asked if the participants had education about sexual health in their schools. Similarly, in the 19th question, the participants were asked whether they find themselves as educated about safe sexual intercourse as an individual or not. In the survey, it was asked whether they needed more guidance and training concerning their approach towards LGBTQIA+ individuals as a physician. The answers given to the questions are summarized in Table 6.

One thousand ninety-nine $(98.5 \%)$ of the participants declared that they would examine an LGBTQIA+ patient, while $13(1.2 \%)$ of them indicated that they would refuse to examine. There were $4(0.4 \%)$ missing data.

Six hundred and eighty (60.9\%) participants considered LGBTQIA+ individuals more prone to catching sexually transmitted diseases, while $375(33.6 \%)$ of the participants did not. Twenty-seven (2.4\%) participants chose the answer "sometimes," and 23 (2.1\%) did not have a particular idea. There were 11 (1.0\%) missing data.

Participants were also asked if they would treat their patients differently who had a lifestyle that they did not approve of. Seventy-six (6.8\%) of them said "yes," 996
$(89.2 \%)$ of them said "no," $40(3.6 \%)$ of them said "sometimes," and $3(0.3 \%)$ of them did not have a particular idea. There was $1(0.1 \%)$ missing data. The results of the comparison between the 1st and 6th-grade students are shown in Table 7, 8, and 9.

There is a statistically significant difference between the answers given by 1st and 6th grade students to the 15th question asking whether LGBTQIA+ individuals have the right to adoption or not, to the 18th question asking if their school is providing education on sexual health, to the 19th question asking if they consider themselves educated about safe sexual intercourse as an individual and to the 22nd question asking if they think that LGBTQIA+ individuals are more prone to catching sexually transmitted diseases $(\mathrm{p}<0.005)$. 
Table 2: Medical school grades' distribution of the participants.

\begin{tabular}{ccc} 
Grades & Number of students (n) & Percentage (\%) \\
\hline $\mathbf{1}$ & 263 & 23.6 \\
$\mathbf{2}$ & 315 & 28.2 \\
$\mathbf{3}$ & 179 & 16.0 \\
$\mathbf{4}$ & 112 & 10.0 \\
$\mathbf{5}$ & 98 & 8.8 \\
$\mathbf{6}$ & 139 & 12.5 \\
Missing & 10 & 0.9 \\
Total & 1116 & 100.0 \\
\hline
\end{tabular}

Table 3: Sexual orientations of the medical students.

\begin{tabular}{ccc} 
Sexual orientation & Number of students (n) & Percentage (\%) \\
\hline Heterosexual & 971 & 87.0 \\
Bisexual & 54 & 4.8 \\
Homosexual & 38 & 3.4 \\
I do not prefer to specify & 37 & 3.3 \\
Other & 7 & 0.6 \\
Pansexual & 4 & 0.4 \\
Asexual & 3 & 0.3 \\
Heteroflexible & 1 & 0.1 \\
Missing & 1 & 0.1 \\
Total & 1116 & 100.0 \\
\hline
\end{tabular}

Table 4: Numeric data of the answers of questions 14 and 15.

Question 14

\begin{tabular}{ccccc}
\hline Answers & $\begin{array}{c}\text { Number of } \\
\text { students (n) }\end{array}$ & Percentage (\%) & $\begin{array}{c}\text { Number of } \\
\text { students (n) }\end{array}$ & Percentage (\%) \\
\hline Yes & 887 & 79.5 & 758 & 67.9 \\
No & 184 & 16.5 & 276 & 24.7 \\
Other & 29 & 2.6 & 45 & 4.0 \\
No idea & 9 & 0.8 & 32 & 2.9 \\
Missing & 7 & 0.6 & 5 & 0.5 \\
Total & 1116 & 100.0 & 1116 & 100.0 \\
\hline
\end{tabular}


Table 5: Sexual behaviors of LGBTQIA+ individuals.

\begin{tabular}{ccc} 
Answers & Number of students (n) & Percentage (\%) \\
\hline Same with heterosexual & 572 & 40.5 \\
More complicated & 383 & 27.1 \\
Safer & 288 & 20.4 \\
No idea & 49 & 3.5 \\
Cannot be generalized & 29 & 2.1 \\
Unhealthy & 15 & 1.0 \\
Other & 5 & 0.4 \\
Missing & 64 & 4.5 \\
Total & 10 & 0.7 \\
\hline
\end{tabular}

Table 6: Numeric data of the answers of questions 18, 19 and 20.

Question $18 \quad$ Question $19 \quad$ Question 20

\begin{tabular}{ccccccc}
\hline Answers & $\begin{array}{c}\text { Number of } \\
\text { students } \\
(\boldsymbol{n})\end{array}$ & $\begin{array}{c}\text { Percentage } \\
(\%)\end{array}$ & $\begin{array}{c}\text { Number of } \\
\text { students } \\
(\boldsymbol{n})\end{array}$ & $\begin{array}{c}\text { Percentage } \\
(\%)\end{array}$ & $\begin{array}{c}\text { Number of } \\
\text { students } \\
(\boldsymbol{n})\end{array}$ & $\begin{array}{c}\text { Percentage } \\
(\%)\end{array}$ \\
\hline Yes & 495 & 44.4 & 883 & 79.1 & 857 & 76.8 \\
No & 552 & 49.5 & 196 & 17.6 & 240 & 21.5 \\
Partially & 43 & 3.9 & 30 & 2.7 & 14 & 1.3 \\
No idea & 15 & 1.3 & 3 & 0.3 & 0 & 0.0 \\
Missing & 11 & 1.0 & 4 & 0.4 & 5 & 0.5 \\
Total & 1116 & 100.0 & 1116 & 100.0 & 1116 & 100.0 \\
\hline
\end{tabular}


Table 7: Comparison of the $1^{\text {st }}$ and $6^{\text {th }}$ graders' answers by percentage.

\begin{tabular}{|c|c|c|c|c|c|}
\hline Grades & & & & & $\boldsymbol{P}$ \\
\hline Questions/Answers & Yes & No & Yes & No & \\
\hline $\begin{array}{l}\text { Do you consider yourself a } \\
\text { religious person? }\end{array}$ & $35.6 \%$ & $64.4 \%$ & $36.2 \%$ & $63.8 \%$ & 0.905 \\
\hline $\begin{array}{l}\text { Is there someone who is } \\
\text { LGBTQIA+ among your } \\
\text { friends, relatives or people } \\
\text { aroundyou? }\end{array}$ & $61.7 \%$ & $38.3 \%$ & $52.2 \%$ & $47.8 \%$ & 0.067 \\
\hline $\begin{array}{l}\text { Would you accept an } \\
\text { LGBTQIA+ individual as your } \\
\text { friend? }\end{array}$ & $91.6 \%$ & $8.4 \%$ & $84.8 \%$ & $15.2 \%$ & 0.038 \\
\hline $\begin{array}{l}\text { Do you think LGBTQIA+ } \\
\text { people have psychological } \\
\text { disorders and need therapy? }\end{array}$ & $21.1 \%$ & $78.9 \%$ & $26.8 \%$ & $73.2 \%$ & 0.195 \\
\hline $\begin{array}{l}\text { Do you think that accepting } \\
\text { LGBTQIA+ individuals as } \\
\text { "normal" will benefit our } \\
\text { society? }\end{array}$ & $81.6 \%$ & $18.4 \%$ & $72.5 \%$ & $27.5 \%$ & 0.035 \\
\hline $\begin{array}{l}\text { Do you find it appropriate to } \\
\text { allow LGBTQIA+ individuals to } \\
\text { work with children? }\end{array}$ & $83.1 \%$ & $16.9 \%$ & $71.7 \%$ & $28.3 \%$ & 0.008 \\
\hline $\begin{array}{l}\text { Do you think LGBTQIA+ } \\
\text { individuals are mistreated in } \\
\text { your society? }\end{array}$ & $90.4 \%$ & $9.6 \%$ & $84.8 \%$ & $15.2 \%$ & 0.093 \\
\hline $\begin{array}{l}\text { Do you think LGBTQIA+ } \\
\text { individuals should be fully } \\
\text { accepted in our society? }\end{array}$ & $79.6 \%$ & $20.4 \%$ & $72.5 \%$ & $27.5 \%$ & 0.106 \\
\hline $\begin{array}{l}\text { Would you refuse to see a } \\
\text { patient because they are an } \\
\text { LGBTQIA+ individual? }\end{array}$ & $0.8 \%$ & $99.2 \%$ & $1.4 \%$ & $98.6 \%$ & 0.611 \\
\hline
\end{tabular}

Table 8: Comparison of 1st and 6th graders' answers to gender by number and percentage.

\begin{tabular}{|c|c|c|c|c|c|c|c|}
\hline \multirow{2}{*}{$\begin{array}{c}\text { Grade } \\
\text { Gender/ } \\
\text { statistics }\end{array}$} & \multicolumn{3}{|c|}{$I^{\text {st }}$ grade } & \multicolumn{3}{|c|}{$6^{\text {th }}$ grade } & \multirow{2}{*}{$\begin{array}{c}P \\
\text { value }\end{array}$} \\
\hline & Number & $\begin{array}{l}\% \text { within the } \\
\text { class }\end{array}$ & $\begin{array}{l}\text { \% within the } \\
\text { comparison }\end{array}$ & Number & $\begin{array}{l}\% \text { within } \\
\text { the class }\end{array}$ & $\begin{array}{l}\text { \% within the } \\
\text { comparison }\end{array}$ & \\
\hline Homosexual & 12 & $4.6 \%$ & $70.6 \%$ & 5 & $3.6 \%$ & $29.4 \%$ & 0.327 \\
\hline Heterosexual & 219 & $83.9 \%$ & $64.0 \%$ & 123 & $89.1 \%$ & $36.0 \%$ & 0.327 \\
\hline Bisexual & 16 & $6.1 \%$ & $80.0 \%$ & 4 & $2.9 \%$ & $20.0 \%$ & 0.327 \\
\hline Asexual & 1 & $0.4 \%$ & $100.0 \%$ & 0 & $0.0 \%$ & $0.0 \%$ & 0.327 \\
\hline $\begin{array}{c}\text { I do not } \\
\text { prefer to } \\
\text { specify }\end{array}$ & 9 & $3.4 \%$ & $60.0 \%$ & 6 & $4.3 \%$ & $40.0 \%$ & 0.327 \\
\hline Pansexual & 1 & $0.4 \%$ & $100.0 \%$ & 0 & $0.0 \%$ & $0.0 \%$ & 0.327 \\
\hline Other & 3 & $1.1 \%$ & $100.0 \%$ & 0 & $0.0 \%$ & $0.0 \%$ & 0.327 \\
\hline
\end{tabular}


Table 9: Comparison of 1st and 6th graders' answers by percentage.

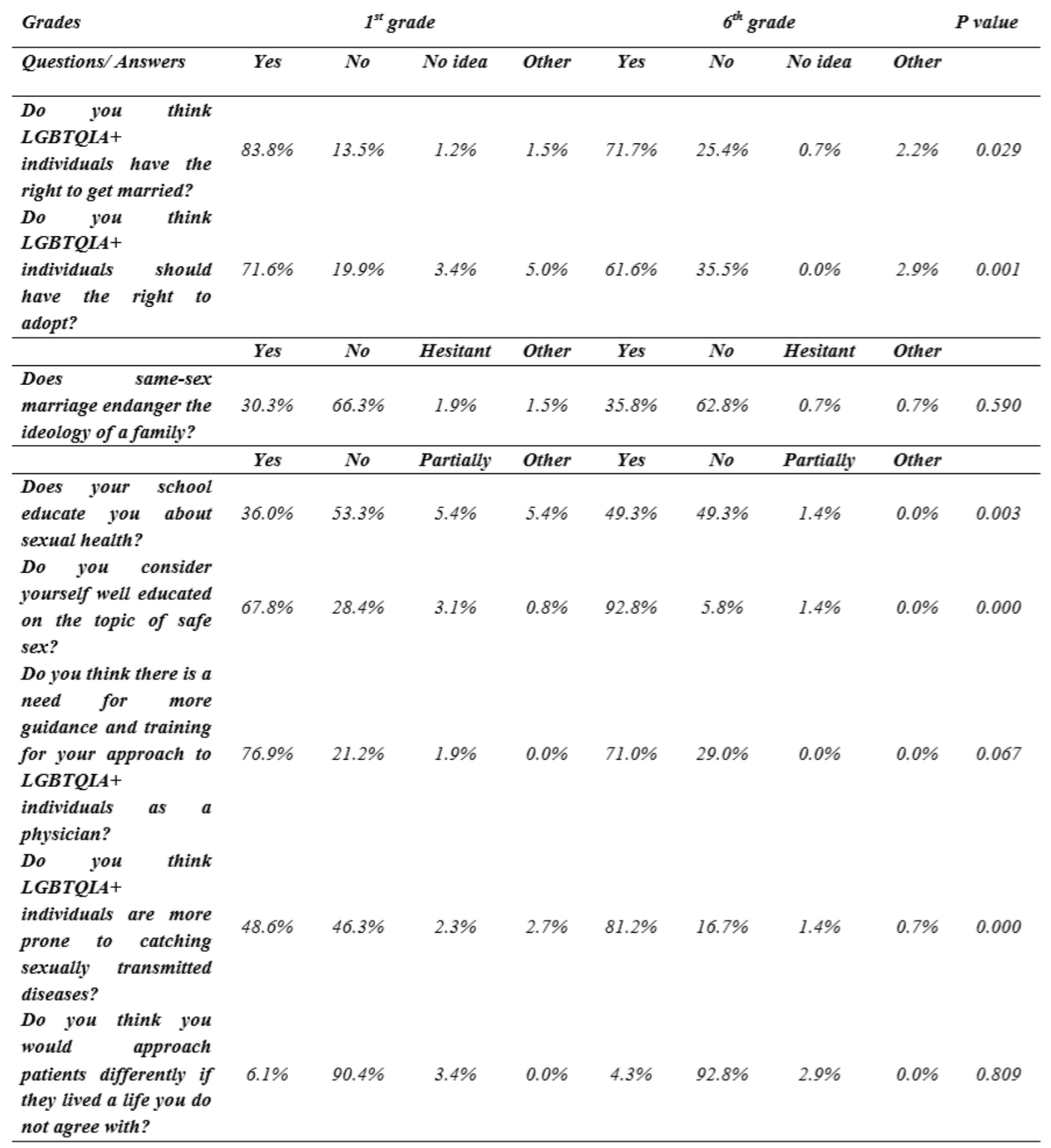




\section{(TMS}

\section{DISCUSSION}

Although it has been 47 years since the removal of homosexuality as a "behavioral disorder" subdivision from DSM, the perspective of professionals towards LGBTQIA+ patients remains an important issue $(13,14)$. For example, according to a study conducted by Yilmaz et al. (15), nearly $8 \%$ of LGBT individuals cancel or postpone physicians' visits with the fear of being discriminated against or judged (15). Therefore, our study, which was conducted on Turkish, German, and Bosnian medical schools aimed to evaluate the attitude of medical students towards the LGBTQIA+ community.

A similar study conducted at Ege University School of Medicine's fourth and fifth-grade students by Ertuğrul et al. (16) aimed to assess the medical students' attitude towards LGBTQIA+ patients. Their questionnaire also consisted of questions regarding the participants' gender, sexual orientation, and possible approaches to LGBTQIA+ patients. In their study, 83.5\% of the participants identified themselves as heterosexual while the rest of the students were distributed as $7.8 \%$ bisexual, $2.9 \%$ asexual, $1.9 \%$ gay, and $1 \%$ lesbian which is very similar to our results (16). The general distribution of sexual orientation was also similar in a study conducted by Liang et al. (17) at Boston University School of Medicine. This could indicate that the distribution of sexual orientation does not differ drastically from country to country. Based on their findings, Ertuğrul et al. (16) also stated that $52.4 \%$ of the participants could be influenced by their beliefs, feelings, or thoughts while interviewing a patient. In our study, participants were asked if they would have treated a patient differently with a lifestyle outside of their approval, and 89.2\% said "No." In comparison with their study, they included the participants' high schools, their learning resources regarding the concept of LGBTQIA+, and three patient scenarios to question students' approaches in the questionnaire. Our study aimed to acquire a general opinion of medical students from all grades and different schools, whereas Ertuğrul et al. (16) mainly focused on determining the approach of the future doctor (4th and 5th-year medical students) towards LGBTQIA+ individuals by asking more scenario-based questions.

Another study conducted on Hong Kong Chinese medical students by Hon et al. (18) evaluates the medical students' attitudes and personal experiences regarding homosexuality. In their cross-sectional study, $38 \%$ of the students stated that they had homosexual friends (18).

Comparatively, the percentage of students who have an LGBTQIA+ friend/relative was higher $(57.3 \%)$ in our study. This variation could be a result of the wider defi- nition of the focus group in our study. Eighty-six percent of their participants said that they would accept a homosexual individual as their friend, and our studies' findings were also similar (18). As their data implied, 25\% of the students had thought that homosexuals have psychological disorders and need therapy (18). In our study, the same question was asked for LGBTQIA+ individuals, and the result was similar. The study conducted by Hon et al. (18) was specific for homosexuality, whereas our study had a wider scope on the subject.

In our study, $76.8 \%$ of the participants agreed that there should be more guidelines and training regarding physicians' approaches towards LGBTQIA+ patients. In a survey study conducted on Canadian medical students, $84.5 \%$ of the students have also expressed the necessity of further education regarding the issues of the LGBTQIA+ community (19).

Our study also included an open-ended question, asking the participants to explain in a few sentences how they would approach an LGBTQIA+ patient. Many participants have responded that they would treat them the same way they treated other patients. Some participants have also added that they would be more mindful of infections and/or diseases that have a higher prevalence in the LGBTQIA+ community. Some participants expressed that they would refuse to examine the patient. One notable answer stated that the participant would avoid physical contact if the LGBTQIA+ patient is the same gender as he/she is. This negative behavior of some participants towards LGBTQIA+ individuals may indicate either homophobic notions or lack of knowledge about LGBTQIA+ community. The open-ended questions also showed the awareness of many medical students about the necessity of making LGBTQIA+ individuals more comfortable. "As a physician, I will either have a rainbow flag in my room or a rainbow pin on my uniform. Because the smallest support can have a lifelong impact on our relationship with the patients." was noted as one of the remarkable answers. Besides, one of the answers from a Turkish participant expressed his concern regarding the medical computer systems allowing only two genders as possible entries. This is only one of many indications that systematic changes are required in medical systems and communities to provide more inclusion and representation.

The comparison of the answers given by 1 st and 6th-grade students disclose a clear difference between the attitude of these two groups of medical students. One of the most noticeable differences was that while $16 \%$ of 1 st-grade students stated to be LGBTQIA+, this proportion was $11 \%$ amongst the 6th-grade students. Collateral to this, 1st-grade students have more LGBTQIA 
people as their friends or relatives. Around 36\% of the students in both groups stated that they consider themselves religious, however, when examined, their outlook on LGBTQIA+ individuals was quite different. This may be further indication that religion may not have a direct effect on the way certain participants would approach LGBTQIA+ individuals. For instance, $26.8 \%$ of 6th-grade students still consider LGBTQIA+ people as psychologically ill, while this proportion is lower by $5.7 \%$ among 1st-grade students. Similar differences can be seen on further questions in the survey, revealing the higher tendency of intolerance amongst 6th-grade students. The results in a study conducted by White et al. (20) are similar to ours when it comes to lower grade students, $86.0 \%$ of the 2 nd-year students stated they would feel more comfortable examining an LGBT patient compared to $82.1 \%$ of 3 rd and higher-grade students. One more noteworthy study by Nama et al. (19) found more accepting and positive answers from younger individuals regarding the LGBTQIA+ community. This gap could be attributed to the absence of LGBTQIA+ related didactic material in the medical curriculum or the incline of the younger students to be more open-minded to different lifestyles.

Another comparison can be made according to the statistically significant difference found among the groups when asked if the participant thinks LGBTQIA+ individuals are more prone to sexually transmitted diseases. Eighty-one percent of 6th-grade students answered "yes," as the percentage of this answer was $48.6 \%$ among the 1st-grade students. Some students emphasized the fact that practicing same-sex intercourse, especially in the male population, without proper protection is a risk factor for certain sexually transmitted diseases.

On the other hand, taking into account the lack of knowledge 1st-grade students have about sexually transmitted diseases compared to the 6th-grade students, there is a possibility they may have overlooked this aspect while answering the question. This comparison does not necessarily mean that 6th-grade students are more biased towards the LGBTQIA+ patients, which is still a possibility that they may have answered the question from a different point of view.

There was also a statistically significant difference found among the 1st and 6th-grade students' answers to whether they consider themselves educated about safe sexual intercourse. This could be associated with many factors such as age, individual experiences, and knowledge. Moreover, there was also a statistically significant difference found among the groups whether their school provided them with education on sexual health. However, this is not enough to explain the aforementioned differences, since the participants in our study are from various schools and countries with different curriculums which may or may not include safe sexual practices.

Bearing in mind that 6 th-grade students are going to be enrolled in the medical field as physicians in the following year, the higher prevalence of the negative perspective spotted may be a major issue for LGBTQIA+ patients in the future. A review published by Gates et al. (21) points out that around $4 \%$ of the American population is openly LGBTQIA+ individuals. Assuming this, the rate would not drastically vary between countries meaning that every physician will supposedly encounter hundreds of LGBTQIA+ patients throughout their professional careers. Even though nearly $90 \%$ of the participants stated they would not treat their LGBTQIA+ patients any different, several studies demonstrate that LGBTQIA+ patients feel uncomfortable being treated by a physician who lacks sensitivity or information about their sexual orientation $(22,23)$. All of these factors endanger the proper utilization of healthcare services LGBTQIA+ individuals will receive. The importance of proper education about the LGBTQIA+ people should once again be taken into consideration.

Several studies have shown that it is not only possible to have a positive outcome by incorporating diversity in educational programs towards raising awareness, but also how fast this outcome could be (24). As a great model, Kelley et al. (24) demonstrated how it is possible to positively change perspective, raise awareness and increase the number of people willing to treat LGBTQIA+ patients among medical students' by implementing LGBT health in their curriculum in University of California.

Our study has several limitations. First of all, the participants of the study were not randomly selected, they voluntarily took part in the survey. This might have had a more positive impact on our results owing to students who are already more accepting and informed about LGBTQIA+ individuals to gravitate towards filling out our survey. Furthermore, the participants were not evenly distributed among grades. The difference in numbers might have affected the distribution of the answers. Despite the data privacy and informed consent statement at the beginning of the survey, participants might have had concerns regarding the data security of the survey. This might have influenced the accuracy of some answers given, especially to questions on more sensitive topics, such as the sexual orientation of the participant. Furthermore, some questions in the survey were limited to only allowing "yes" and "no" as answers. This not only ignores the possible answers in-between, but also forces the students, who have not had thought about the certain topic of the question, to pick one answer. Some partici- 
pants have also expressed their opinions about how certain questions were phrased. For example, in the case of question 10 which is phrased as: "Do you think it would be beneficial to the society to recognize LGBTQIA+ individuals as 'normal'?", a participant has stated that this question could be answered in two different ways. The participant's answers were "Yes-normalizing the perception would cause an individual to behave differently in a negative manner. No- categorizing the LGBT community as normal would contradict with the concepts of freedom and diversity."

In conclusion, though the majority of answers given indicate a positive approach towards LGBTQIA+ individuals, it can be stated that the attitude of medical students towards LGBTQIA+ individuals is by far suboptimal, especially taking the positively leaning nature of the conducted study into consideration. For instance, a quarter of participants still consider homosexuality as a psychological disorder. Despite this, most of the participating students stated that they would accept LGBTQIA+ individuals as their patients. Yet it is open to discussion on how comfortable these individuals would feel being examined by medical professionals not approving their sexual orientation. It should also be stated that medical students with a positive perspective towards LGBTQIA+ individuals seem to be more aware of the importance of how much their comfort would benefit the healthy relationship between the physician and the patient. Another important result of the study has shown that the vast majority of the students do not think that they are properly being educated about the correct way to approach LGBTQIA+ individuals. Proper education about the sexual health issues and gender minorities in the medical curriculum could play a crucial role in raising social awareness and overcoming prejudices among medical students. Further studies are needed to thoroughly understand the medical students' perspectives on LGBTQIA+ community and patients.

Ethics Committee Approval: This study was approved by the Scientific Research Ethics Committee of Trakya University School of Medicine (Protocol Code: TÜTF-BAEK 2019/355).

Informed Consent: Informed consent was obtained from the participants of this study.

Conflict of Interest: The authors declared no conflict of interest. Author contributions: Concept: FEA, AK Design: FEA, AK Supervision: SO Resources: FEA, BK, AK, BA, KÇ, CG, NK, BK, BG, SO Materials: FEA, BK, AK, BA, KÇ, CG, NK, BK, BG, SO Data collection and/or processing: FEA, BK, AK, BA, KÇ, CG, NK, BK, BG Analysis and/or Interpretation: FEA, BK, AK, BA, KÇ, CG, NK, BK, BG, SO Literature Search: FEA, BK, AK, BA, KÇ, CG, NK, BK, BG,
SO Writing Manuscript: FEA, BK, AK, BA, KÇ, CG, NK, BK, BG, SO Critical Review: FEA, BK, AK, BA, KÇ, CG, NK, BK, BG, SOTD.

Financial disclosure: The authors declared that this study received no financial support.

Editor-in-chief's Note: Seven authors of this article, Fatih Erkan Akay, Beliz Koçyiğit, Kaan Çifçibaşı, Çağrı Girit, Nazlıcan Kükürtcü, Berra Kurtoğlu, and Bengisu Gür are members of the editorial board of Turkish Medical Student Journal. However, they did not take place in any stage on the editorial decision of the manuscript. The editors who evaluated this manuscript are from other institutions.

\section{REFERENCES}

1. McGuire TR. Is homosexuality genetic? A critical review and some suggestions. J Homosex 1995;28(1-2):115-45.

2. Rubinstein G. The decision to remove homosexuality from the DSM: twenty years later. Am J Psychother 1995;49(3):416-27.

3. Spitzer RL. The diagnostic status of homosexuality in DSM-III: a reformulation of the issues. Am J Psychiatry 1981;138(2):210-5.

4. Starr P. The social transformation of American medicine. 2nd ed. New York: Basic Books; 1982.

5. Boehmer U. Twenty years of public health research: inclusion of lesbian, gay, bisexual, and transgender populations. Am J Public Health 2002;92(7):1125-30.

6. Obedin-Maliver J, Goldsmith ES, Stewart L et al. Lesbian, gay, bisexual, and transgender-related content in undergraduate medical education. JAMA 2011;306(9):971-7.

7. Dean L, Meyer IH, Robinson K et al. Lesbian, gay, bisexual, and transgender health: findings and concerns. Journal of the Gay and Lesbian Medical Association 2000;4(3):1-51.

8. Lee R. Health care problems of lesbian, gay, bisexual, and transgender patients. West J Med 2000;172(6):403-8.

9. Burke BP, White JC. The well-being of gay, lesbian, and bisexual physicians. West J Med 2001;174(1):59-62.

10. $\mathrm{Ng} \mathrm{H}$. Lesbian, gay, bisexual, and transgender health and medical education. JAMA 2011;306(21):2326-7.

11. Fikar CR, Keith L. Information needs of gay, lesbian, bisexual, and transgendered health care professionals: results of an internet survey. J Med Libr Assoc 2004;92(1):56-65.

12. Simkin RJ. Not all your patients are straight. CMAJ 1998;159(4):370-5.

13. Mathews WC, Booth MW, Turner JD et al. Physicians' attitudes toward homosexuality - survey of a California county medical society. West J Med 1986;144(1):106-10.

14. Lim FA, Brown DV Jr, Justin Kim SM. Addressing health care disparities in the lesbian, gay, bisexual, and transgender population: a review of best practices. Am J Nurs 2014;114(6):24-34.

15. Yllmaz V, Göçmen İ. Türkiye'de lezbiyen, gey, biseksüel ve trans (LGBT) bireylerin sosyal ve ekonomik sorunları araştırmasının özet sonuçları. Research Turkey. 2015;4(6):94-101.

16. Ertuğrul Ş, Batı AH. Tip öğrencilerinin LGBTİ+ hastalara yaklaşımı. Tıp Eğitimi Dünyası 2019;18(56):81-94. 


\section{(2TMSJ}

17. Liang JJ, Gardner IH, Walker JA et al. Observed deficiencies in medical student knowledge of transgender and intersex health. Endocr Pract 2017;23(8):897-906.

18. Hon KE, Leung T, Yau AP et al. A survey of attitudes toward homosexuality in Hong Kong Chinese medical students. Teaching and Learning in Medicine. 2005;17(4):344-8.

19. Nama N, MacPherson P, Sampson M et al. Medical students' perception of lesbian, gay, bisexual, and transgender (LGBT) discrimination in their learning environment and their self-reported comfort level for caring for LGBT patients: a survey study. Med Educ Online 2017;22(1):1368850.

20. White W, Brenman S, Paradis E et al. Lesbian, gay, bisexual, and transgender patient care: medical students' preparedness and comfort. Teach Learn Med 2015;27(3):254-63.

21. Gates GJ. LGBT demographics: comparisons among population-based surveys. UCLA: The Williams Institute 2014. Available from: URL:https://escholarship.org/uc/item/0kr784fx.

22. Davis RM, Genel M, Howe JP et al. Health care needs of gay men and lesbians in the United States. JAMA 1996;275(17):1354-9.

23. A provider's handbook on culturally competent care: lesbian, gay, bisexual and transgender population. 1st ed. California: Kaiser Permanente; 2000.

24. Kelley L, Chou CL, Dibble SL et al. A critical intervention in lesbian, gay, bisexual, and transgender health: knowledge and attitude outcomes among second-year medical students. Teach Learn Med 2008;20(3):248-53. 